\title{
Effects of a continuous rate infusion of butorphanol in isoflurane-anesthetized horses on cardiorespiratory parameters, recovery quality, gastrointestinal motility and serum cortisol concentrations ${ }^{1}$
}

\author{
Bianca Paludeto Dias, Marcelo Augusto de Araújo", Maurício Deschk ${ }^{\mathrm{III}}$, Thomas Alexander Trein ${ }^{\mathrm{IV}}$, Nirmem Carlos Pinheirov, \\ Silvia Helena Venturolli Perri ${ }^{\mathrm{VI}}$, Celso Antônio Rodrigues ${ }^{\mathrm{VII}}$, Paulo Sergio Patto dos Santos ${ }^{\mathrm{VIII}}$
}

DOI: http://dx.doi.org/10.1590/S0102-86502014001900006

IMaster, Program in Animal Science, Faculty of Veterinary Medicine, Sao Paulo State University (UNESP), Araçatuba-SP, Brazil. Acquisition of data, technical procedures, manuscript writing.

"Master, Faculty of Veterinary Medicine and Animal Science, Federal University of Mato Grosso do Sul (UFMS), Campo Grande-MS, Brazil. Acquisition of data, technical procedures.

IIIFellow PhD degree, Program in Animal Science, Faculty of Veterinary Medicine, UNESP, Araçatuba-SP, Brazil. Acquisition of data, technical procedures.

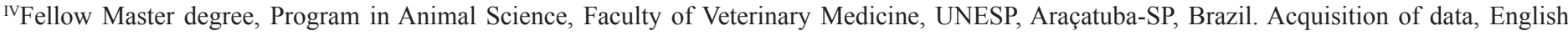
language.

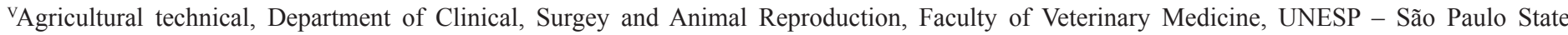
University, Araçatuba-SP. Acquisition of data, technical procedures

VIPhD, Assistant Professor, Department of Support, Animal Production and Health Faculty of Veterinary Medicine, UNESP, Araçatuba-SP, Brazil. Technical procedures, statistical analysis

VIIPhD, Associate Professor, Department of Surgery and Anesthesiology, Faculty of Veterinary Medicine and Animal Science, UNESP, Botucatu-SP, Brazil. Critical revision.

VIII PhD, Assistant Professor, Department of Clinical, Surgery and Animal Reproduction, Faculty of Veterinary Medicine, UNESP, Araçatuba-SP, Brazil. Conception, design, intellectual and scientific content of the study; statistical analysis.

\begin{abstract}
PURPOSE: To assess the cardiorespiratory parametes, recovery, gastrointestinal motility and serum cortisol concentrations in horses anesthetized with isoflurane with or without a continuous rate infusion (CRI) of butorphanol for orchiectomy.

METHODS: Twelve adult, intact, male horses weighing $332 \pm 55 \mathrm{~kg}$ were included in the study. Xilazine was administered as premedication. Anesthesia was induced with ketamine and midazolam and maintained with isoflurane. Butorphanol $\left(0.025 \mathrm{mg} \mathrm{kg}^{-1}\right.$ bolus) or an equivalent volume of saline $(0.9 \%)$ was given intravenously followed by a CRI of butorphanol (BG) (13 $\mu \mathrm{g} \mathrm{kg} \mathrm{k}^{-1}$ hour $\left.{ }^{-1}\right)$ or saline (CG). Cardiorespiratory variables were recorded before (T0) and every 15 minutes for 75 minutes after the start of infusion. Serum cortisol concentration was measured at T0 and 60 minutes, and 30 minutes and 19 hours after the horse stood up. Recovery from anesthesia was evaluated using a scoring system. Gastrointestinal motility was evaluated before anesthesia and during 24 hours after recovery.

RESULTS: There were no significant differences between groups in cardiopulmonary variables, or recovery scores or serum cortisol concentrations. A reduction in gastrointestinal motility was recorded for 60 minutes in BG.

CONCLUSIONS: Continuous rate infusion of butorphanol in horses anesthetized with isoflurane did not adversely affect the cardiopulmonary variables monitored, or recovery scores. A small but statistically significant reduction in gastrointestinal motility occurred in the butorphanol group.
\end{abstract}

Key words: Blood Gas Analysis. Analgesics, Opioid. Anesthesia, Inhalation. Orchiectomy. Horses. 


\section{Introduction}

Inhalation anesthesia is associated with a dose-dependent cardiovascular and respiratory depression ${ }^{1}$. Balanced anesthesia is often used to decrease inhalant anesthetic requirement, thereby limiting cardiovascular depressant effects and providing additional analgesia $^{2,3}$.

Butorphanol, a synthetic narcotic agonist-antagonist ( $\mu$ -receptor antagonist and k-receptor agonist), is commonly used in equine medicine and is considered an efficacious and safe visceral analgesic in adult horses ${ }^{4-6}$. Causes minimal cardiovascular and respiratory effects in adult horse $\mathrm{e}^{7,8}$ and contributes to the management of balanced anesthesia ${ }^{9}$.

The use of butorphanol in horses with abdominal pain is controversial. Even though it provides considerable visceral analgesia, it promotes gastrointestinal changes, decrease in gastrointestinal sounds, reduction in fecal output, and production of dry feces, as well as changes in behavior such as excitement, increased locomotor activity, tremors, pawing and ataxia ${ }^{6}$.

According to Sellon et al. ${ }^{8}$, a continuous rate infusion (CRI) of butorphanol at $23 \mu \mathrm{g} \mathrm{kg}^{-1}$ hour-1 in healthy horses, compared to a bolus administration of $0.13 \mathrm{mg} \mathrm{kg}^{-1}$ in the immediate postoperative period, was useful for pain management. The continuous rate infusion had less impact upon gastrointestinal function than the bolus. Moreover, the use of a continuous rate infusion for postoperative analgesia in horses with colic $\left(13 \mu \mathrm{g} \mathrm{kg}^{-1}\right.$ hour $^{-1}$ ) provided less weight loss and faster hospital discharge ${ }^{10}$.

The purpose of this study was to investigate the changes in cardiopulmonary parameters, serum cortisol concentrations, quality of recovery, and postoperative gastrointestinal motility in horses isoflurane-anesthetized and submitted a CRI of butorphanol. The authors hypothesized that a CRI of butorphanol would not cause clinically relevant changes in cardiopulmonary variables and postoperative gastrointestinal motility, but would improve the quality of recovery and decrease serum cortisol concentrations.

\section{Methods}

The study and experimental design were approved by the local Institutional Animal Care and Use committee (protocol number 005866). Twelve adult, intact, male horses aged $3 \pm 1$ years and weighing $332 \pm 55 \mathrm{~kg}$ were included in the study. All the horses were healthy as determined by physical examination and whole blood count. The animals were equally and randomly distributed into two groups, butorphanol group (BG) and control group (CG), and submitted to orchiectomy.
Food and water were withheld 12 and 4 hours, respectively, prior to anesthesia. On the day of the experiment, a 14-gauge catheter (Insyte, BD, Juiz de Fora-MG, Brazil) was aseptically inserted into each jugular vein for administration of drugs and intraoperative fluid.

Benzathine penicillin G, (22,000 IU kg-1; Pentabiótico reforçado, Fort Dodge Animal, Campinas-SP, Brazil) was administered intramuscularly (IM) before anesthesia.

All horses were premedicated with xylazine $(0.5 \mathrm{mg}$ kg-1; 20 mg mL-1; Dopaser, Calier, Osasco-SP, Brazil) by intravenous (IV) injection. Anesthesia was induced 10 minutes later by ketamine $(1.8 \pm 0.6 \mathrm{mg} \mathrm{kg-1;} 100 \mathrm{mg} \mathrm{mL}-1$; Vetaset, Ford Dodge, Campinas-SP) and midazolam (0.05 mg kg-1; 5 mg mL-1; Dormire; Cristalia, São Paulo-SP, Brazil).

Immediately after induction, the horses were intubated with an endotracheal tube, positioned in dorsal recumbency and maintained on isoflurane (Isoforine, Cristalia, São Paulo-SP) vaporized in oxygen at a flow rate of $15 \mathrm{~mL} \mathrm{~kg}^{-1}$ minute ${ }^{-1}$, using a calibrated vaporizer (HB, São Paulo-SP) and a rebreathing circuit (Conquest Big, HB, São Paulo-SP). The end-tidal isoflurane concentration was maintained at $1.5 \pm 0.2 \%$ and measured using a digital gas analyzer using infrared absorption (DX-2020, gas analyzer module; Dixtal, Manaus-AM, Brazil). Samples were continuously aspirated from a sample line connected between the endotracheal tube and the breathing circuit. Lactated Ringer's solution (Glicolabor, Ribeirão Preto-SP, Brazil) was infused at 3 $\mathrm{mL} \mathrm{kg}^{-1}$ hour ${ }^{-1}$ during anesthesia.

A 20-gauge catheter (Insyte, BD, Juiz de Fora-MG) was placed in a facial artery for arterial pressure measurement and blood sample collection for blood gas analysis. After a mean stabilization period of 35 minutes, a loading dose of butorphanol $\left(0.025 \mathrm{mg} \mathrm{kg}^{-1} ; 10 \mathrm{mg} \mathrm{mL}^{-1}\right.$; Torbugesic, Fort Dodge, Campinas-SP) was administered IV over 1 minute in $\mathrm{BG}$, followed immediately by a CRI of the opioid at the rate of $13 \mu \mathrm{g} \mathrm{kg}^{-1}$ hour $^{-1}$, as described by Sellon et al. ${ }^{8}$, using an syringe pump (ST680, Samtronic, São Paulo-SP). The same methodology was instituted in $\mathrm{CG}$, however, substituting the opioid with $0.9 \%$ sodium chloride solution (Glicolabor, Ribeirão Preto-SP) which was administered at the same volume and rate as butorphanol.

The animals were initially allowed to breath spontaneously. However, when the end-tidal carbon dioxide tension $\left(\mathrm{PE}^{\prime} \mathrm{CO}_{2}\right)$ reached $80 \mathrm{mmHg}$, mechanical ventilation was instituted. Intermittent positive pressure ventilation (IPPV) was achieved by adjusting the ventilator to cycle at a peak inspiratory pressure of $15 \mathrm{cmH}_{2} \mathrm{O}$ and respiratory rate $\left(\mathrm{f}_{\mathrm{R}}\right)$ of 6 breaths minute $\mathrm{e}^{-1}$. 
Measurements were started immediately before administration of butorphanol or saline (T0). Subsequent recordings were at 15 minute intervals after the start of the CRI for a total of 75 minutes (T15, T30, T45, T60, T75). The studied variables were as follows: heart rate $(H R)$, respiratory rate $\left(f_{R}\right)$, rectal temperature (RT), systolic, diastolic and mean arterial pressure (SAP, DAP, MAP), end-tidal carbon dioxide tension $\left(\mathrm{PE}^{\prime} \mathrm{CO}_{2}\right)$, oxyhemoglobin saturation $\left(\mathrm{SpO}_{2}\right)$, partial pressure of arterial oxygen $\left(\mathrm{PaO}_{2}\right)$, partial pressure of arterial carbon dioxide $\left(\mathrm{PaCO}_{2}\right)$, arterial oxyhemoglobin saturation $\left(\mathrm{SaO}_{2}\right)$, bicarbonate $\left(\mathrm{HCO}_{3}^{-}\right)$and arterial $\mathrm{pH}(\mathrm{pHa})$.

Twenty minutes after the loading dose, local blockade of the spermatic cord was carried out in all animals using a 1:1 combination of lidocaine $\left(20 \mathrm{mg} \mathrm{mL}{ }^{-1}\right.$, Xylestesin; Cristalia, São Paulo-SP) and bupivacaine (5 mg mL-1 ${ }^{1}$, Bupi; Cristalia, São Paulo-SP), infiltrating a total of $10 \mathrm{~mL}$ into each spermatic cord. Orchiectomy started at T35 and finished immediately before T45. The surgical procedure was performed by the same surgeon, in order to ensure a standardized surgical time and technique.

Isoflurane and the butorphanol infusion were discontinued after T75 and the horses were transported to the recovery stall. The quality of anesthetic recovery was evaluated using scores, according to the scale proposed by Borges et $a l .{ }^{11}$ : score 1 , excellent (stands at first attempt, after the animal assumes sternal recumbency); score 2, very good (stands at second or third attempt, after the animal assumes sternal recumbency); score 3 , good (stands at fourth attempt, after the animal assumes sternal recumbency; without excitation); score 4 , regular (stands after more than four attempts, after the animal assumes sternal recumbency; significant ataxia); and score 5, poor (multiple attempts to stand; evident excitation; high risk of injuries).

Blood was collected for measurement of serum cortisol concentration at $\mathrm{T} 0, \mathrm{~T} 60$, and $30(\mathrm{~T}+30)$ and 1140 $(\mathrm{T}+1140)$ minutes after the animal stood up (approximately 2 and 19 hours after surgery, respectively). In order to minimize the effects of the circadian variation of cortisol, animals from both groups were equally distributed into two periods: morning and evening. Therefore, of the six animals belonging to each experimental group, three underwent anesthesia and surgery during the morning and the rest during the evening. Eight $\mathrm{mL}$ of venous blood (jugular vein) were collected in $10 \mathrm{~mL}$ assay tubes, without anticoagulant, which were refrigerated for 2 to 4 hours at the temperature of $5{ }^{\circ} \mathrm{C}$. They were then centrifuged (3000 rpm for 10 minutes) to obtain serum and stored in $1.5 \mathrm{~mL}$ microtubes (eppendorf) at $-20{ }^{\circ} \mathrm{C}$. The samples were analyzed using radioimmunoassay, using Coat-A-Count Cortisol kit (Cortisol Coat-a-Count, Genese, Cambuci-RJ, Brazil).

After surgery, local dressing was applied with povidone iodine (Iodopovidona 10\%, Icarai, Santa Rita do Passa QuatroSP, Brazil) and insect repellent (Cidental, Mogivet, Mogi das Cruzes-SP, Brazil). Flunixin meglumine (1.1 mg kg-1; Banamine; $50 \mathrm{mg} \mathrm{mL}^{-1}$; Fort Dodge, Campinas-SP) IV was administered in the immediate postoperative period and at the same dose IM every 24 hours for two days.

Following recovery from anesthesia, gastrointestinal motility was evaluated by abdominal auscultation using a stethoscope, according to Teixeira-Neto et al. ${ }^{12}$. This evaluation was always performed by the same evaluators, unaware of the treatment. For this, the abdomen was divided into four quadrants: right ventral, left ventral, right dorsal and left dorsal. Each quadrant was evaluated for at least 1 minute, with an interval of a few seconds between them. A subjective score was designated for each quadrant ( 0 - no intestinal sounds; 1 - low pitched crepitant sounds, frequency of one per minute; 2- low pitched crepitant sounds, frequency of one to two per minute; 3 loud borborygmi sounds, frequency of one per minute; 4- loud borborygmi sounds, frequency of more than two per minute). The intervals for this evaluation were as follows: TB (baseline; before the anesthetic procedure), $\mathrm{T}+30$ (30 minutes after the animal assumes a standing position) and at 60, 120, 180 and 240 minutes $(\mathrm{T}+60, \mathrm{~T}+120, \mathrm{~T}+180$ and $\mathrm{T}+240)$, and every 5 hours, over 24 hours $(\mathrm{T}+540, \mathrm{~T}+840, \mathrm{~T}+1140$ and $\mathrm{T}+1440$, respectively). (Figure 1)

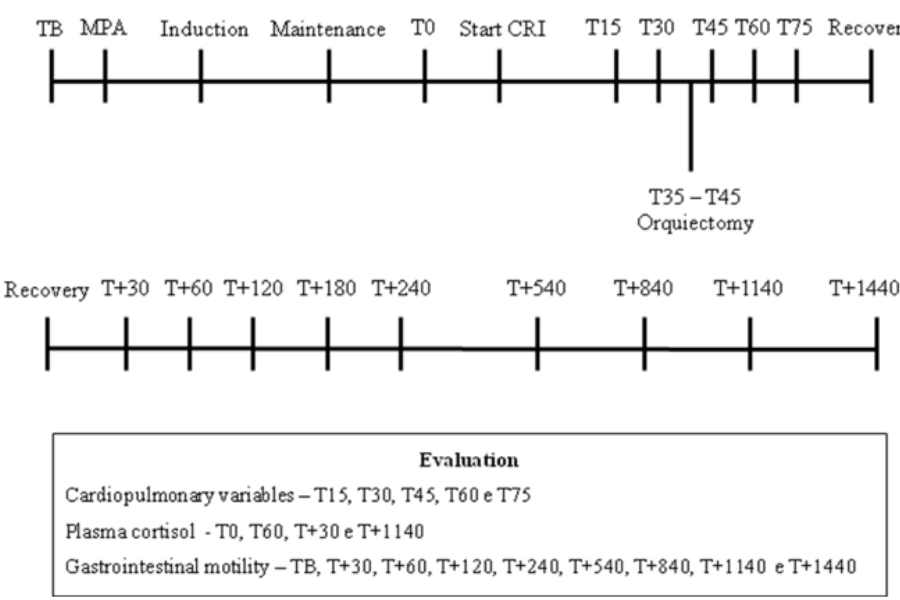

FIGURE 1 - Time line of evaluations in horses anesthetized with isoflurane and treated with $0.9 \% \mathrm{NaCl}$ solution (CG) or with butorphanol (BG). 


\section{Statistical analysis}

All values, with the exception of the intestinal motility variable, were expressed as mean \pm standard deviation. All variables were subjected to the Kolmogorov-Smirnov test for normal distribution. Variables which presented normal distribution were subjected to analysis of variance (ANOVA) and Tukey's post-hoc test to compare values between intervals and groups. Those that did not have normal distribution were subjected to statistical analysis by the Mann-Whitney test. Fisher's exact test was conducted to determine if the butorphanol had interference in respiratory control and need for IPPV. The statistical analysis was performed on a standard computer using Graphpad Instat software
(Graphpad InStat version 3.05, Graphpad Software, San Diego, CA, USA). A $\mathrm{p} \leq 0.05$ was considered statistically significant.

\section{Results}

The cardiopulmonary parameters and blood gas values did not show any significant difference between the groups (Tables 1 and 2). Three animals in BG and one in CG required controlled ventilation, when the maximum established $\mathrm{PE}^{\prime} \mathrm{CO}_{2}$ value $(80 \mathrm{mmHg}$ ) was reached, but statistically butorphanol had no interference in need of IPPV $(p=0.5455)$. There were no other statistically significant differences between the groups or between times (Tables 1, 2 and 3).

TABLE 1 - Mean \pm standard deviation of cardiopulmonary parameters and rectal temperature obtained in horses anesthetized with isoflurane and treated with $0.9 \% \mathrm{NaCl}$ solution (treatment $\mathrm{C}$ ) or with butorphanol (treatment $\mathrm{B}$ ).

\begin{tabular}{|c|c|c|c|c|c|c|c|}
\hline \multirow[b]{2}{*}{ Variables } & \multirow[b]{2}{*}{ Treatment } & \multicolumn{6}{|c|}{ Times } \\
\hline & & T0 & T15 & T30 & T45 & T60 & T75 \\
\hline Heart rate & $\mathbf{C}$ & $46 \pm 8$ & $45 \pm 7$ & $42 \pm 6$ & $40 \pm 5$ & $41 \pm 7$ & $40 \pm 6$ \\
\hline (beats minute $^{-1}$ ) & B & $43 \pm 6$ & $42 \pm 6$ & $39 \pm 6$ & $38 \pm 5$ & $38 \pm 6$ & $39 \pm 3$ \\
\hline Systolic arterial pressure & $\mathbf{C}$ & $90 \pm 23$ & $105 \pm 17$ & $115 \pm 19$ & $120 \pm 20$ & $114 \pm 16$ & $107 \pm 13$ \\
\hline (mm Hg) & B & $85 \pm 23$ & $92 \pm 18$ & $103 \pm 17$ & $93 \pm 13$ & $108 \pm 22$ & $99 \pm 23$ \\
\hline Diastolic arterial pressure & C & $46 \pm 14$ & $59 \pm 11$ & $71 \pm 7$ & $82 \pm 8$ & $75 \pm 12$ & $68 \pm 13$ \\
\hline (mm Hg) & B & $45 \pm 17$ & $49 \pm 15$ & $64 \pm 22$ & $70 \pm 28$ & $75 \pm 24$ & $73 \pm 19$ \\
\hline Mean arterial pressure & $\mathbf{C}$ & $65 \pm 18$ & $78 \pm 10$ & $87 \pm 9$ & $97 \pm 8$ & $91 \pm 13$ & $85 \pm 14$ \\
\hline (mm Hg) & B & $58 \pm 20$ & $66 \pm 16$ & $80 \pm 20$ & $76 \pm 21$ & $87 \pm 23$ & $83 \pm 20$ \\
\hline Respiratory rate & C & $4 \pm 2$ & $4 \pm 2$ & $4 \pm 2$ & $4 \pm 2$ & $5 \pm 1$ & $5 \pm 2$ \\
\hline (breaths minute $^{-1}$ ) & B & $4 \pm 1$ & $3 \pm 2$ & $4 \pm 2$ & $4 \pm 2$ & $5 \pm 2$ & $5 \pm 1$ \\
\hline $\mathrm{SpO}_{2}$ & $\mathbf{C}$ & $95 \pm 3$ & $95 \pm 3$ & $97 \pm 2$ & $96 \pm 3$ & $95 \pm 5$ & $94 \pm 4$ \\
\hline$(\%)$ & B & $96 \pm 4$ & $94 \pm 6$ & $94 \pm 6$ & $94 \pm 6$ & $93 \pm 6$ & $92 \pm 8$ \\
\hline $\mathrm{PE}^{\prime} \mathrm{CO}_{2}$ & $\mathbf{C}$ & $54 \pm 4$ & $55 \pm 4$ & $56 \pm 5$ & $57 \pm 6$ & $55 \pm 8$ & $55 \pm 12^{\mathrm{a}}$ \\
\hline (mm Hg) & B & $58 \pm 16$ & $63 \pm 16$ & $59 \pm 8$ & $57 \pm 11$ & $52 \pm 12$ & $52 \pm 12^{\mathrm{a}}$ \\
\hline Rectal temperature & C & $36.6 \pm 0.7$ & $36.3 \pm 0.7$ & $36.1 \pm 0.6$ & $35.9 \pm 0.4$ & $36.0 \pm 0.6$ & $36.0 \pm 0.5$ \\
\hline$\left({ }^{\circ} \mathrm{C}\right)$ & B & $36.9 \pm 0.6$ & $36.6 \pm 0.7$ & $36.5 \pm 0.7$ & $36.4 \pm 0.7$ & $36.3 \pm 0.7$ & $36.1 \pm 0.7$ \\
\hline
\end{tabular}

$0.9 \% \mathrm{NaCl}$ solution $=$ Butorphanol at all times $(\mathrm{p}<0.05)$

TABLE 2 - Mean \pm standard deviation of arterial $\mathrm{pH}(\mathrm{pHa})$, oxygen partial pressure $\left(\mathrm{PaO}_{2}\right)$, carbon dioxide partial pressure $\left(\mathrm{PaCO}_{2}\right)$, oxyhemoglobin saturation $\left(\mathrm{SaO}_{2}\right)$ and standard bicarbonate $\left(\mathrm{HCO}_{3}^{-}\right)$, obtained in horses anesthetized with isoflurane and treated with $0.9 \% \mathrm{NaCl}$ solution (treatment $\mathrm{C}$ ) or with butorphanol (treatment $\mathrm{B}$ ).

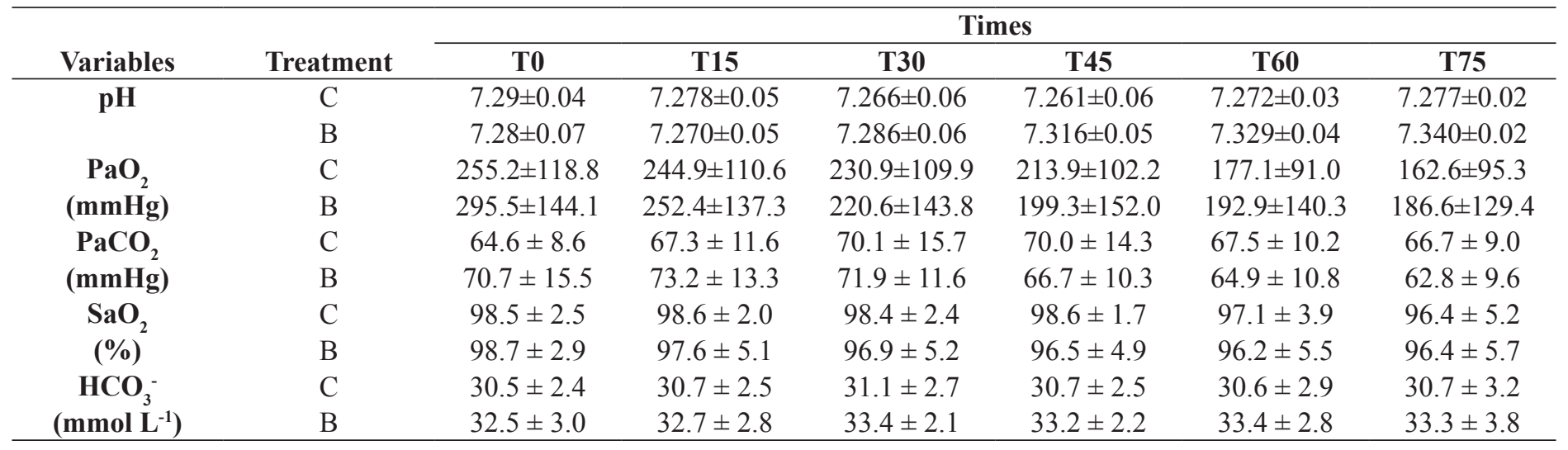

$0.9 \% \mathrm{NaCl}$ solution $=$ Butorphanol at all times $(\mathrm{p}<0.05)$ 
TABLE 3 - Median (Md), minimum and maximum score of recovery, and mean and standard deviation of recovery time, in minutes, obtained in horses anesthetized with isoflurane and treated with $0.9 \% \mathrm{NaCl}$ solution (treatment $\mathrm{C}$ ) or with butorphanol (treatment B).

\begin{tabular}{ccc}
\hline \multirow{2}{*}{ Treatment } & \multicolumn{2}{c}{ Recovery } \\
\cline { 2 - 3 } & $\begin{array}{c}\text { Median score } \\
\text { (min-max) }\end{array}$ & $\begin{array}{c}\text { Time } \\
\text { (mean } \pm \text { standard deviation) }\end{array}$ \\
\hline C & $3(1-5)$ & $21 \pm 6$ \\
B & $3(2-4)$ & $22 \pm 8$ \\
\hline
\end{tabular}

$0.9 \% \mathrm{NaCl}$ solution $=$ Butorphanol at all times $(\mathrm{p}<0.05)$

The median scores of gastrointestinal motility at $\mathrm{T}+30$ and $\mathrm{T}+60$ were significantly higher in CG compared to BG (Table 4). There were no differences in cortisol concentrations between groups (Table 5).

TABLE 4 - Median and minimum and maximum of motility score, at each evaluation obtained in horses anesthetized with isoflurane and treated with $0.9 \% \mathrm{NaCl}$ solution (treatment $\mathrm{C}$ ) or with butorphanol (treatment B).

\begin{tabular}{ccccc}
\hline \multirow{2}{*}{ Times } & \multicolumn{4}{c}{ Motility } \\
\cline { 2 - 5 } & \multicolumn{2}{c}{ Treatment C } & \multicolumn{2}{c}{ Treatment B } \\
\cline { 2 - 5 } T0 & Md & Min - Max & Md & Min - Max \\
\hline $\mathbf{T}+\mathbf{3 0}$ & $12 *$ & $8-16$ & 11 & $8-16$ \\
$\mathbf{T}+\mathbf{6 0}$ & $12 *$ & $11-16$ & $10 *$ & $7-16$ \\
$\mathbf{T}+\mathbf{1 2 0}$ & 16 & $15-16$ & 12 & $9-16$ \\
$\mathbf{T}+\mathbf{1 8 0}$ & 16 & $16-16$ & 16 & $13-16$ \\
$\mathbf{T}+\mathbf{2 4 0}$ & 16 & $15-16$ & 16 & $10-16$ \\
$\mathbf{T}+\mathbf{5 4 0}$ & 16 & $14-16$ & 16 & $14-16$ \\
$\mathbf{T}+\mathbf{8 4 0}$ & 16 & $12-16$ & 16 & $12-16$ \\
$\mathbf{T}+\mathbf{1 1 4 0}$ & 15 & $12-16$ & 14 & $12-16$ \\
$\mathbf{T}+\mathbf{1 4 4 0}$ & 16 & $14-16$ & 16 & $13-16$ \\
\hline
\end{tabular}

* Significant difference between treatments CG ad BG $(\mathrm{p}<0.05)$.

TABLE 5 - Mean and standard deviation of cortisol, in $\mu \mathrm{g} \mathrm{dL}^{-1}$, at each measurement obtained in horses anesthetized with isoflurane and treated with $0.9 \% \mathrm{NaCl}$ solution (treatment $\mathrm{C}$ ) or with butorphanol (treatment B).

\begin{tabular}{ccc}
\hline \multirow{2}{*}{ Times } & \multicolumn{2}{c}{ Cortisol } \\
\cline { 2 - 3 } & Treatment C & Treatment B \\
\hline T0 & $3.33 \pm 2.05$ & $2.81 \pm 1.29$ \\
T60 & $7.77 \pm 2.59$ & $9.88 \pm 2.65$ \\
T +30 & $6.62 \pm 2.43$ & $8.31 \pm 1.89$ \\
T +1140 & $4.64 \pm 1.95$ & $4.91 \pm 1.72$ \\
\hline
\end{tabular}

$0.9 \% \mathrm{NaCl}$ solution $=$ Butorphanol at all times $(\mathrm{p}<0.05)$

\section{Discussion}

The continuous rate infusion of butorphanol did not promote significant changes in cardiopulmonary variables evaluated. This result is consistent with results of previous studies indicating that butorphanol does not significantly alter cardiorespiratory function in horses after administration intramuscular, intravenuous or at continuous rate infusion ${ }^{7,8,13,14}$.

Both groups had respiratory acidosis. Although a larger number of animals in the butorphanol group (3/6) has need of intervention with IPPV to reach the limit for $\mathrm{PE}^{\prime} \mathrm{CO}_{2}$, the statistical analysis showed that the need for IPPV does not depend on butorphanol infusion.

The mean cortisol values found in both groups varied from $2.81 \pm 1.29$ to $9.88 \pm 2.65 \mu \mathrm{g} \mathrm{dL}^{-1}$, suggesting that the animals suffered some degree of pain or stress, as these values were higher than the reference interval for the species (1.3 to $\left.2.9 \mu \mathrm{g} \mathrm{dL}^{-1}\right)$. The mean values in treatment $\mathrm{B}$, despite of no statistical differences, were slightly higher than in treatment $\mathrm{C}$ at $\mathrm{T} 60, \mathrm{~T}+30$ and $\mathrm{T}+1140$. This difference was not anticipated because one would expect that the animals in BG, which received the opioid during the surgical period, would suffer less stress due to the supposed analgesia, as was reported by Sellon et $a l .{ }^{10}$, who observed a reduction in cortisol concentrations in horses submitted to continuous rate infusion of butorphanol after celiotomy. However, it is this increased cortisol could have been caused by the effect of butorphanol, as observed by Pascoe et $a l{ }^{15}$, where the use of a synthetic kappa opioid agonist (U5088H) resulted in increased cortisol concentrations in primates, which was not observed with mu and delta opioid agonists. As in the study of Sanz et al. ${ }^{14}$, where the horses receiving butorphanol as an analgesic in postoperative orchiectomy had higher values of plasma cortisol that horses receiving phenylbutazone.

The quality of recovery (score 3 in both groups) and the time required for anesthetic recovery $(21 \pm 6$ in $\mathrm{CG}$ and $22 \pm 8$ minutes in BG) were equivalent in both groups, in such a way that the continuous rate infusion of butorphanol, in the conditions of this study, did not interfere with these parameters. The same observation was made by Lascurain et $a l^{16}$, who used three different doses of butorphanol (0.025; 0.05 and $\left.0.075 \mathrm{mg} \mathrm{kg}^{-1}\right)$ and did not notice a difference in the quality of recovery in horses.

In this study, a significant reduction in motility was observed between groups at $\mathrm{T}+30$ and $\mathrm{T}+60$, where less motility was observed in BG. Sanchez et al. ${ }^{17}$ obtained different results, observing a clinical reduction in duodenal motility of short duration in horses after a bolus administration of butorphanol at 
the dose of $18 \mu \mathrm{g} \mathrm{kg}^{-1}$, but not after infusion at the rate of $13 \mu \mathrm{g}$ $\mathrm{kg}^{-1}$ hour ${ }^{-1}$ for 2 hours. The same observations were reported by Sellon et al. ${ }^{8}$ using doses of $0.13 \mathrm{mg} \mathrm{kg}^{-1}$ as a bolus, followed by a continuous rate infusion of $13 \mu \mathrm{g} \mathrm{kg}^{-1}$ hour ${ }^{-1}$ for 24 hours.

Similarly, individual variance cannot be excluded as a possible interference factor for the reduction in motility in BG, as one animal from the group showed a more pronounced reduction at baseline compared to the other animals. However, even though a reduction in motility was observed in this study, it is important to recognize that it was observed for a short period of time (60 minutes). Therefore, its use in horses is viable as there was only a slight variation between the maximum and minimum values in the groups. Hence, it is likely that this is of minimal clinical importance as the animals did not show signs of discomfort or pain, and fed normally.

\section{Conclusions}

The continuous rate infusion of butorphanol in horses anesthetized with isoflurane and submitted to orchiectomy did not cause cardiopulmonary changes, but promoted decrease in gastrointestinal motility during the first 60 minutes after anesthetic recovery. The opioid infusion did not improve the quality of recovery or decrease plasma cortisol concentrations.

\section{References}

1. Grosenbaugh DA, Muir WW. Cardiorespiratory effects of sevoflurane, isoflurane, and halothane anesthesia in horses. Am J Vet Res. 1998 Jan;59(1):101-6. PMID: 9442252.

2. Ringer SK, kalchofner K, Boller J, Fürst A, Bettschart-Wolfensberger R. A clinical comparison of two anaesthetic protocols using lidocaine or medetomidine in horses. Vet Anaesth Analg. 2007 Jul;34(4):25768. doi: 10.1111/j.1467-2995.2006.00321.x.

3. Valverde A. Balanced anesthesia and constant-rate infusions in horses. Vet Clin North Am Equine Pract. 2013 Apr;29(1):89-122. doi: 10.1016/j.cveq.2012.11.004.

4. Kalpravidh M, Lumb WV, Wright M, Heath RB. Analgesic effects of butorphanol in horses: Dose-response studies. Am J Vet Res. 1984 Feb;45(2): 211-6. PMID: 6711944.

5. Muir WW, Robertson JT. Visceral analgesia: Effects of xylazine, butorphanol, meperidine, and pentazocine in horses. Am J Vet Res. 1985 Oct;46(10):2081-4. PMID: 4062010.

6. Skarda TR, Muir WW. Comparison of electroacupuncture and butorphanol on respiratory and cardiovascular effects and rectal pain threshold after controlled rectal distention in mares. Am J Vet Res. 2003 Feb;64(2):137-44. doi: 10.2460/ajvr.2003.64.137.

7. Robertson JT, Muir WW, Sans R. Cardiopulmonary effects of butorphanol tartrate in horses. Am J Vet Res. 1981 Jan;42(1):41-4. PMID: 7224316.

8. Sellon DC, Monroe VL, Roberts MC, Papich MG. Pharmacokinetics and adverse effects of butorphanol administered by single intravenous injection or continuous infusion in horses. Am J Vet Res. 2001 Feb;62(2):183-9. doi: 10.2460/ajvr.2001.62.18.
9. Caure S, Cousty M, Tricaud C. Effects of adding butorphanol to a balanced anaesthesia protocol during arthoroscopic surgery in horses. Vet Rec. 2010 Mar;166(11):324-8. doi: 10.1136/vr.b4799.

10. Sellon DC, Roberts MC, Blikslager AT, Ulibarri C, Papich MG. Effect of continuous intravenous of butorphanol on physiologic and outcome variables in horses after celiotomy. J Vet Intern Med. 2004 Jul-Aug;18(4):555-63. doi: 10.1111/j.1939-1676.2004.tb02585.x.

11. Borges JHS, Souza AH, Dória RGS, Canola, JC, Santos, PSP, Valadão, CAA. Efeitos da cetamina $\mathrm{s}(+)$ em equinos anestesiados pelo halotano. Cienc Anim Bras. 2010 Jan-Mar;11(1):141-8. doi: 10.5216/cab.v11i1.4107.

12. Teixeira Neto FJ, McDonell WN, Black WD, Duronghphongtorn S. Effects of glycopyrrolate on cardiopulmonary function in horses anesthetized with halothane and xylazine. Am J Vet Res. 2004 Apr;65(4):456-63. doi: 10.2460/ajvr.2004.65.456.

13. Hofmeister EH, Mackey EB, Trim CM. Effect of butorphanol administration on cardiovascular parameters in isofluraneanesthetized horses - a retrospective clinical evaluation. Vet Anaest Analg. 2008 Jan;35(1):38-44. doi: 10.1111/j.14672995.2007.00355.x.

14. Sanz MG, Sellon DC, Cary JA, Hines MT, Famsworth KD. Analgesic effects of butorphanol tartrate and phenylbutazone administered alone and in combination in young horses undergoing routine castration. J Am Med Vet Assoc. 2009 Nov;235(10):1194203. doi: 10.2460/javma.235.10.1194.

15. Pascoe JE, Williams KL, Mukhopadhyaya P, Rice KC, Wooks $\mathrm{JH}, \mathrm{Ko}$ MC. Effects of mu, kappa and delta opioid receptor on the function of hypothalamic-pituitary-adrenal axis in monkeys. Psychoneuroendocrinology 2008 May;33(4):478-86. doi: 10.1016/j. psyneuen.2008.01.006.

16. Lascurain AAG, Lopez HS, Steffey EP, Doherty PS, Hernandez EN. The influence of butorphanol dose on characteristics of xylazine-butorphanol-propofol anesthesia in horses in altitude. Vet Anaesth Analg. 2006 Mar;33(2):104-10. doi: 10.1111/j.14672995.2005.00237.x.

17. Sanchez LC, Elfenbein JR, Robertson SA. Effect of acepromazine, butorphanol or N-butylscopolammonium bromide on visceral and somatic nociception and duodenal motility in conscious horses. Am J Vet Res. 2008 May;69(5):579-85. doi: 10.2460/ajvr.69.5.579.

\section{Correspondence:}

Paulo Sergio Patto dos Santos

Rua Clovis Pestana, 793

16050-680 Araçatuba - SP Brasil

Tel.: (55 18)3211-1433

patto@fmva.unesp.br

Received: Aug 11, 2014

Review: Oct 13, 2014

Accepted: Nov 14, 2014

Conflict of interest: none

Financial source: Sao Paulo Research Foundation (FAPESP - process number 03390-6)

${ }^{1}$ Research performed at Large Animal Hospital, Department of Clinical, Surgery and Animal Reproduction, Faculty of Veterinary Medicine, Sao Paulo State University (UNESP), Araçatuba-SP, Brazil. Part of Master degree thesis, Postgraduate Program in Animal Science, Faculty of Veterinary Medicine, UNESP. Tutor: Paulo Sergio Patto dos Santos. 